\title{
PERSISTENT LEFT SUPERIOR VENA CAVA: AN UNUSUAL CAUSE OF SUBDIVIDED LEFT ATRIUM
}

\author{
Christian Kreutzer, MD, ${ }^{\mathrm{a}, \mathrm{b}}$ Gabriel Santiago, MD, ${ }^{\mathrm{a}}$ Roald Fernando Varon, MD, ${ }^{\mathrm{a}}$ Maria Ines Roman, MD, \\ Maria Grippo, MD, ${ }^{\mathrm{c}}$ Haydee Vazquez, MD, ${ }^{\mathrm{d}}$ Andres J. Schlichter, MD, ${ }^{\mathrm{a}}$ and Guillermo O. A. Kreutzer, MD, \\ Buenos Aires, Argentina
}

The persistence of a left superior vena cava (SVC) draining into the coronary sinus has been described as the most common thoracic venous anomaly and is present in about $3 \%$ to $10 \%$ of patients with congenital heart disease. Moreover, it has been reported as an anatomic finding without hemodynamic consequences unless associated with an unroofed coronary sinus. In 1987, however, Ascuitto and colleagues ${ }^{1}$ reported a case in which a left SVC produced a subdivided left atrium.

We report five consecutive cases and one early case in which a persistent left SVC produced a ridge in the left atrium, causing a subdivided left atrium. The aim of this report is to draw attention to this rare diagnosis as an unusual cause of obstruction to pulmonary venous flow.

Patients and methods. From April 1993 to December 1995, five patients with atrial septal defect (ASD), persistent left SVC draining in the coronary sinus, and diverse associated anomalies were operated on in the Children's Hospital "Ricardo Gutierrez" of Buenos Aires and Bazterrica Clinic. Demographic and anatomic characteristics of the patients are summarized in Table I. The diagnosis of persistent left SVC was made by two-dimensional echocardiography (ECHO-2D) in these five patients and confirmed by cardiac catheterization and angiography in two. ECHO-2D showed a dilated coronary sinus and a ridge coursing diagonally along the inner aspect of the posterior wall of the left atrium. This divided the left atrium into two chambers: one proximal, where all the pulmonary veins drained normally, and one distal, which contained the left atrial appendage and mitral valve. ECHO-2D in one patient with associated tetralogy of Fallot revealed a "small" left ventricle with an enddiastolic volume of $20 \mathrm{ml} / \mathrm{m}^{2}$ body surface. At follow-up, all patients were studied with color-Doppler echocardiography, and the diastolic function was evaluated by transmitral flow.

From the Division of Cardiovascular Surgery, ${ }^{a}$ Cardiac Intensive Care Unit, ${ }^{\mathrm{b}}$ Cardiology Services, ${ }^{\mathrm{c}}$ Echocardiography Section, ${ }^{\mathrm{d}}$ and Bazterrica Clinic, Children's Hospital "Ricardo Gutierrez" of Buenos Aires, Buenos Aires, Argentina.

Received for publication July 9, 1997; accepted for publication July 17, 1997.

Address for reprints: Christian Kreutzer, MD, Instructor in Cardiovascular Surgery, Children's Hospital "Ricardo Gutierrez" of Buenos Aires, Gallo 1330 (1425), Buenos Aires, Argentina.

J Thorac Cardiovasc Surg 1998;115:462-4

Copyright (c) 1998 by Mosby, Inc.

0022-5223/98 $\$ 5.00+0 \quad \mathbf{1 2 / 5 4 / 8 4 7 2 8}$
Another patient was operated on in 1983 for a partial atrioventricular communis and preoperative trivial mitral regurgitation, with cleft closure and ostium primum ASD closure with a pericardial patch. This patient died unexpectedly with pulmonary edema and high left atrial pressure. This case called our attention to a anomaly that had not been described at that time.

Surgical technique. Through a median sternotomy, the left SVC was carefully evaluated, as was the presence of the innominate vein. We have observed that the left SVC is shorter in this entity, producing some degree of traction on the posterior wall of the left atrium. When the innominate vein was absent and the right SVC was hypoplastic, the dominant left SVC was temporary occluded, and if the pressure in the venous line of the left arm rose above $20 \mathrm{~mm} \mathrm{Hg}$, a Pacifico DLP cannula (Medtronic DLP, Grand Rapids, Mich.) was placed in the left SVC, leaving enough room for the placement of a conduit between the two SVCs. Ascending aorta, SVC, and inferior vena cava were cannulated, and cardiopulmonary bypass was started. After aortic crossclamping and administration of cardioplegic solution, the right atrium was opened, the ASD was inspected, and a markedly dilated coronary sinus was confirmed. At close inspection of the left atrium through the ASD, a ridge produced by the impingement of the left SVC was noted. The ridge divided the left atrium into two chambers: one proximal, with the pulmonary veins, and one distal, with the left atrial appendage and mitral valve.

The coronary sinus was completely unroofed (Fig. 1, $A$ ), and the tissue forming the ridge was completely excised. The ASD was closed with an autologous pericardial patch, and the coronary sinus was closed with continuous suture (Fig. 1, B). Complete repair of the associated anomalies was performed after that. Once the aortic crossclamp had been released, the left SVC was sectioned and divided to eliminate the tension on the posterior aspect of the left atrium. It is remarkable that once divided the distance between the two ends was usually more than $10 \mathrm{~mm}$. In two patients with absence of the innominate vein, an $8 \mathrm{~mm}$ polytetrafluoroethylene conduit was placed between the two SVCs.

Results. All of the consecutive patients have had an uneventful recovery. Patients with ASD and ventricular septal defect were extubated on postoperative day 1 ; the patient with tetralogy of Fallot required the infusion of dopamine and amrinone to improve diastolic function and was extubated on postoperative day 3. Postoperative Doppler echocardiography in this patient showed a "restrictive" filling pattern of the left ventricle by transmitral flow. Mean length of stay was 7 days. At follow-up, all 

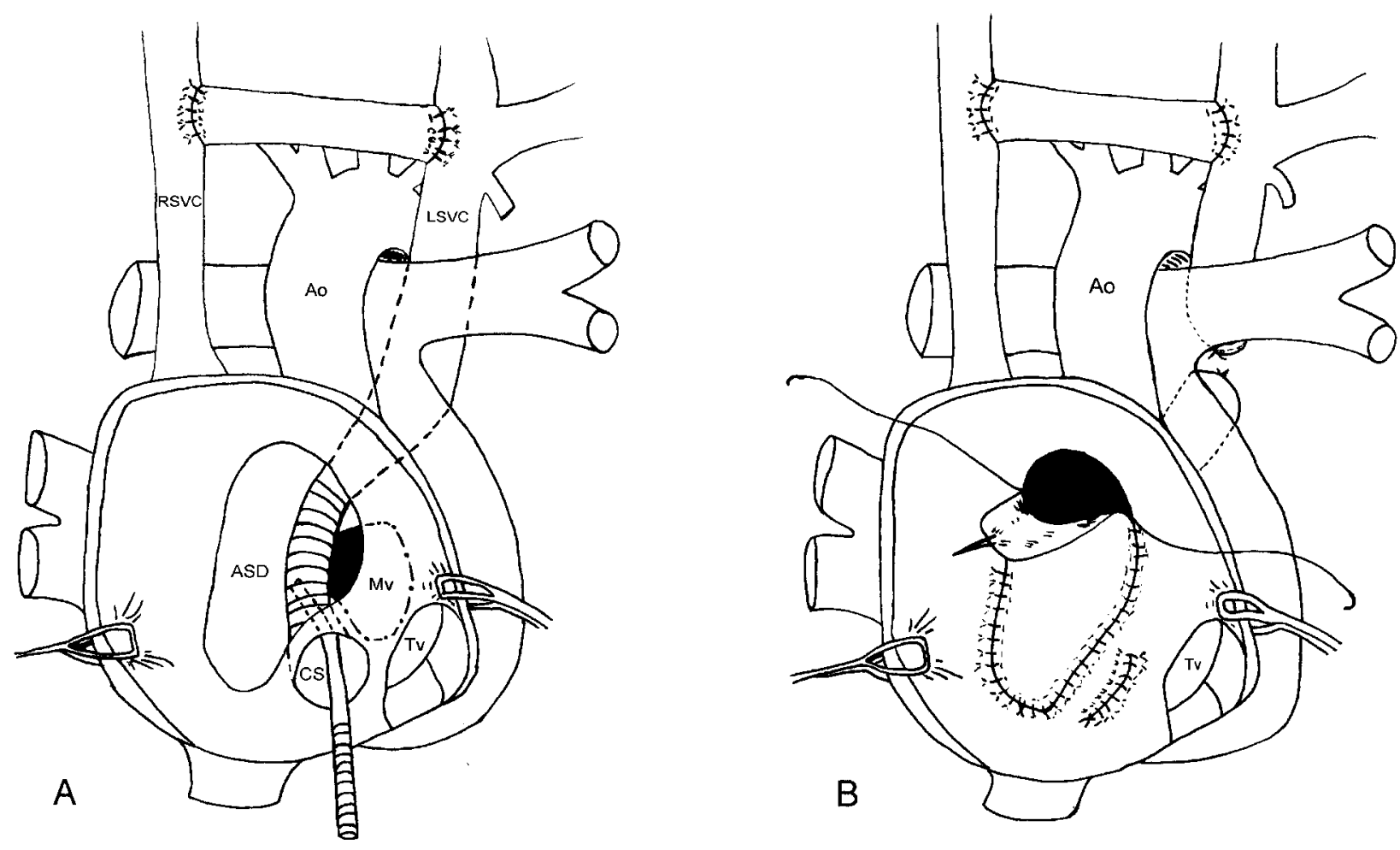

Fig. 1. A, The coronary sinus is completely unroofed and the tissue that formed the ridge is completely excised. B, The ASD is closed with an autologous pericardial patch and the coronary sinus is closed with continuous suture. $R S V C$, Right SVC; $L S V C$, left SVC; $A o$, aorta; $M v$, mitral valve; $C S$, coronary sinus; $T v$, tricuspid valve.

Table I. Cases of persistent left SVC: Clinical data

\begin{tabular}{clccc}
\hline Case & \multicolumn{1}{c}{$\begin{array}{c}\text { Associated } \\
\text { anomalies }\end{array}$} & $\begin{array}{c}\text { Age } \\
(\text { mo })\end{array}$ & $\begin{array}{c}\text { Weight } \\
(\mathrm{kg})\end{array}$ & CHF \\
\hline 1 & Tetralogy of Fallot, OS ASD & 24 & 12 & No \\
2 & Small peri VSD, OS ASD & 22 & 11 & Yes \\
3 & Small peri VSD, OS ASD & 24 & 10 & Yes; Qp/Qs $=4.2$ \\
4 & OS ASD, abs IV & 7 & 6 & Yes, severe; Qp/Qs $=4.7$ \\
5 & OS ASD, Abs IV & 6 & 4.5 & Yes \\
Early case & Partial AVC & 12 & 6 & Yes
\end{tabular}

$C H F$, Congestive heart failure; TOF, tetralogy of Fallot; $O S$, ostium secundum; peri, perimembranous; VSD, ventricular septal defect; $Q p / Q s$, pulmonary/ systemic flow ratio; $A V C$, atrioventricular communis.

patients remain well and free of medication. ECHO-2D showed normal diastolic function by transmitral flow and left ventricular volumes in all patients.

The autopsy of the patient operated on in 1983 showed a subdivided left atrium and a severe flow obstruction to the mitral chamber produced by the ridge in the posterior aspect and by the ASD patch in the anterior aspect, a good mitral valve repair, and no residual ASD. Left ventricular dimensions were small but within normal ranges.

Comments. It has been postulated that the abnormal membrane of the typical cor triatriatum may be induced by persistent left SVC impinging on the posterior wall of the primitive left atrium. ${ }^{2,3}$ In the particular group of patients described here, a ridge produced by the left SVC subdivided the left atrium into two chambers, as in classic cor triatriatum type $\mathrm{Ab}$ : one proximal, with the pulmonary veins, and one distal, with the mitral valve. These patients had a preoperative diagnosis of persistent left SVC draining into the coronary sinus. In this series, two patients with ASD had severe congestive heart failure. This could be explained by an obligatory shunt at the level of the left atrium. In the patient with tetralogy of Fallot, ${ }^{4}$ the presence of the anomaly produced a "small" left ventricle according to ECHO-2D, and it was important to have the preoperative diagnosis to achieve a successful 
correction. When tetralogy of Fallot is associated with small left ventricle, the presence of a left SVC should be considered. In the case without preoperative diagnosis of subdivided left atrium, the consequence was fatal; the patient died in the cardiac intensive care unit of pulmonary edema with high left atrial pressure on the first postoperative day. We hypothesize that the obstruction was created by the ASD closure. Furthermore, we believe that this anomaly should be considered when pulmonary venous flow obstruction is suspected and is not explained by pulmonary vein stenosis, total anomalous pulmonary venous return, typical cor triatriatum, left atrial myxomas, or mitral valve anomalies. $^{5}$

In conclusion, we advocate the close inspection of the left atrium in patients with persistent left SVC. In the presence of a ridge, the coronary sinus should be unroofed and the left SVC should be divided to completely eliminate the tension on the posterior aspect of the left atrium.

\section{REFERENCES}

1. Ascuitto RJ, Ross-Ascuitto NT, Kopf GS, Fahey J, Kleinmann CS, Hellenbrand WE, et al. Persistent left superior vena cava causing subdivided left atrium: diagnosis, embryological implications, and surgical management. Ann Thorac Surg 1987;44: 546-9.

2. Gharagozloo F, Bulkley BH, Hutchings GM. A proposed pathogenesis of cor triatriatum: impingement of the left superior vena cava on the developing left atrium. Am Heart J 1977;94:618-26.

3. Thilenius OJ, Bharati S, Lev M. Subdivided left atrium: an expanded concept of cor triatriatum sinistrum. Am J Cardiol 1976;37:743-52.

4. Binotto MA, Aiello VD, Ebaid M. Coexistence of divided left atrium (cor triatriatum) and tetralogy of Fallot. Int J Cardiol 1991;31:97-9.

5. Radermecker MA, Grenade T, Jalali H, Legrand V, de Leval MR. An unusual case of cor triatriatum: clinical presentation and haemodynamics of a rare anomaly. Cardiovasc Surg 1993;1:83-5. 